Braz J Med Biol Res, January 2011, Volume 44(1) 11-15

doi: 10.1590/S0100-879X2010007500114

Wrist ultrasound analysis of patients with early rheumatoid arthritis

J.A. Mendonça, M.A. Yazbek, I.M.M. Laurindo and M.B. Bertolo

The Brazilian Journal of Medical and Biological Research is partially financed by
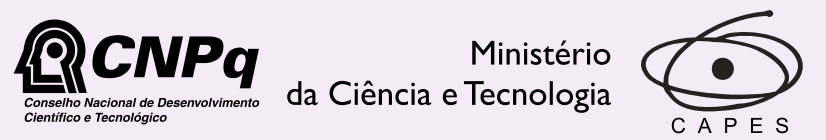

Ministério da Educação

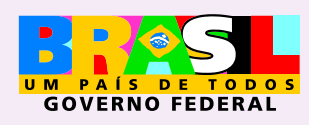

ATAPESP

Institutional Sponsors
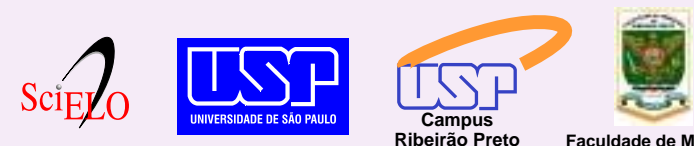

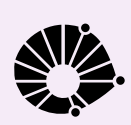

UNICAMP
Ф SHIMADZU

GE Healthcare
Hotsite of proteomics metabolomics developped by: 


\title{
Wrist ultrasound analysis of patients with early rheumatoid arthritis
}

\author{
J.A. Mendonça ${ }^{1}$, M.A. Yazbek ${ }^{1}$, I.M.M. Laurindo ${ }^{2}$ and M.B. Bertolo ${ }^{1}$ \\ ${ }^{1}$ Serviço de Reumatologia, Faculdade de Ciências Médicas, \\ Universidade Estadual de Campinas, Campinas, SP, Brasil \\ ${ }^{2}$ Serviço de Reumatologia, Faculdade de Medicina, \\ Universidade de São Paulo, São Paulo, SP, Brasil
}

\begin{abstract}
In the present study, we evaluated 42 wrists using the semi-quantitative scales power Doppler ultrasound (PDUS) and gray scale ultrasound (GSUS) with scores ranging from 0 to 3 and correlated the results with clinical, laboratory and radiographic data. Twenty-one patients (17 women and 4 men) with rheumatoid arthritis according to criteria of the American College of Rheumatology were enrolled in the study from September 2008 to July 2009 at Universidade Estadual de Campinas (UNICAMP). The average disease duration was 14 months. The patients were $66.6 \%$ Caucasians and $33.3 \%$ non-Caucasians, with a mean age of 42 and 41 years, respectively. A dorsal longitudinal scan was performed by ultrasound on the radiocarpal and midcarpal joints using GE LOGIQ XP-linear ultrasound and a high frequency (8-10 MHz) transducer. All patients were X-rayed, and the Larsen score was determined for the joints, with grades ranging from 0 to $\mathrm{V}$. This study showed significant correlations between clinical, sonographic and laboratory data: GSUS and swollen right wrist $(r=0.546)$, GSUS of right wrist and swelling of left wrist ( $r$ $=0.511)$, PDUS of right wrist and pain in left wrist $(r=0.436)$, PDUS of right wrist and C-reactive protein $(r=0.466)$. Ultrasound can be considered a useful tool in the diagnosis of synovitis in early rheumatoid arthritis mainly when the anti-cyclic citrullinated peptide and rheumatoid factor are negative, and can lead to an early change in the therapeutic decision.
\end{abstract}

Key words: Power Doppler ultrasound; Gray scale ultrasound; Rheumatoid arthritis; Wrist; Synovitis

\section{Introduction}

Joint ultrasound has proved to be an important tool to evaluate synovitis, which could be considered the first abnormality in early rheumatoid arthritis (RA) (1-4). X-ray has been the method most frequently used to assess bone and joints, but an important drawback is that it does not show lesions in soft tissues in the early stage of disease (5-7).

Ultrasound is a sensitive technique for the detection of synovitis, effusion and bone erosion in RA, often difficult to determine by clinical assessment and traditional radiography $(6,7)$. Subclinical synovitis can be diagnosed early in inflammatory diseases by ultrasound and its evolution may even be monitored, thus being a precursor of oligoarthritis and polyarthritis (8). Ultrasound facilitates the early detection of arthritis and allows an earlier establishment of therapy (9-12).

\section{Material and Methods}

Twenty-one patients were enrolled from September 2008 to July 2009 at Universidade Estadual de Campi- nas (UNICAMP), Campinas, Brazil. Seventeen women and 4 men were included: $66.6 \%$ Caucasians and $33.3 \%$ non-Caucasians, with a mean age of 42 and 41 years, respectively, with RA according to criteria of the American College of Rheumatology. Gray scale (GS) and power Doppler (PD) ultrasound were applied to patients with early RA and correlated with clinical, laboratory and radiological data. The average disease duration was 14 months since presenting the first sign of arthritis. The medications used by the patients are listed in Table 1.

Clinical evaluation consisted of Disease Activity Score based on 28 joints (DAS28), calculated using the concentration of the C-reactive protein (CRP) or erythrocyte sedimentation rate (ESR). The DAS28 can range from 0 to 10 , and studies have shown that the lower rate of disease activity is $3.2(13)$. This study used DAS28 equal to or greater than 3.2 as inclusion criteria.

The study was approved by the Universidade Estadual de Campinas (UNICAMP) Ethics Committee and all patients

Correspondence: J.A. Mendonça, Rua da Fazenda, 125, Casa 10, Condomínio Dálias, 13175-665 Sumaré, SP, Brasil.

E-mail: mendoncaja@ig.com.br

Received March 10, 2010. Accepted October 7, 2010. Available online October 29, 2010. Published January $17,2011$. 
gave written informed consent after completing the specific quality of life instrument - Health Assessment Questionnaire (HAQ), which evaluates disability, discomfort and pain at the time of the exam $(14,15)$.

The ultrasound was performed with the patient seated and with hands flat on the top of the table. The radiocarpal and midcarpal regions were examined by a dorsal longitudinal scan, when evaluating the cross-scan of the wrist joint. The equipment used was a linear GE LOGIQ XP Ultrasound apparatus (USA) with a high-frequency (8-10 $\mathrm{MHz}$ ) transducer, which accurately shows surface structures such as tendons, synovia, and other structures. All structures were documented to ensure high reproducibility of the results $(16,17)$.

The ultrasound analysis using a GS ultrasound reflects an increase of the synovium as a hypoechoic image and PD ultrasound demonstrates the microcirculation in the phase of synovial hypertrophy, identifying inflammatory activity. Using a semi-quantitative scale, a joint capsule was classified as having a degree of 0 to 3 of synovial proliferation, and a degree of intense or important signal by PD (18-21).

Synovitis was scored by GS ultrasound (GSUS) as 0 = absence, 1 = mild (describes a small hypoechoic/anechoic line beneath the joint capsule), 2 = moderate (the joint capsule is elevated parallel to the joint area), and 3 = severe or marked (characterizes a strong distension of the joint capsule).

Synovitis was scored by PD ultrasound (PDUS) as: $0=$ absence (no intra-articular color signal), $1=$ mild (up to 3 color signals or 2 single and 1 confluent signal in the intra-articular area, 2 = moderate (greater than grade 1 to $<50 \%$ of the intra-articular area filled with color signals), and $3=$ marked $(\geq 50 \%$ of the intra-articular area filled with color signals).

The Doppler settings were optimized to 'low flow', with a medium wall filter (to minimize flash artifact) and a pulse repetition frequency of $800 \mathrm{~Hz}$.

Wrist radiography was performed in all patients and the Larsen score was used to evaluate the aspects in the $\mathrm{X}$-ray. Joints received grades of 0 to $\mathrm{V}$, as follows: grade 0 = normal; grade $\mathrm{I}=$ mild abnormality (presence of one or more of the following lesions: edema of soft tissues, osteopenia around the joint and a slight decrease in joint space); grade II = definite abnormality (presence of small erosions, decreased joint space is not obligatory); grade III
= marked abnormality (presence of erosions and decreased joint space); grade IV = severe abnormality (the original joint surface remains partially preserved), and grade $\mathrm{V}=$ mutilating abnormality (the original joint surface disappeared; huge deformity is present) (22-25).

\section{Results}

\section{Clinical, laboratory and imaging results}

Fourteen $(66.6 \%)$ patients had pain in the right wrist and $13(61.9 \%)$ had pain in the left wrist; $16(76 \%)$ patients had swelling of the right wrist and $14(66.6 \%)$ had swelling of the left wrist. The mean ( \pm SD) DAS28 for this sample was $4.0 \pm 1.1$ (data variation: 0 to 10 ), the mean $\mathrm{HAQ}$ was $1.2 \pm 0.5(0=$ without disability to $3=$ severe disability $)$, with $145.7 \mathrm{IU} / \mathrm{dL}$ (normal <22 IU/dL) anti-cyclic citrullinated peptide (anti-CCP) and the average rheumatoid factor was $231.63 \mathrm{lU} / \mathrm{dL}$ (normal $<20 \mathrm{lU} / \mathrm{dL}$ ). Mean CRP was $6.97 \pm$ $11.13 \mathrm{mg} / \mathrm{dL}$ (normal $>6 \mathrm{mg} / \mathrm{dL}$ ) and mean ESR was $4.7 \pm$ $1.0 \mathrm{~mm}$ (normal >10 mm). Synovitis was detected by GSUS in $66.6 \%(\mathrm{~N}=14)$ and $61.9 \%(\mathrm{~N}=13)$ of right and left wrists, respectively. In the right wrist, the synovitis determined by GSUS was $28.5 \%(\mathrm{~N}=6)$ grade $1,19 \%(\mathrm{~N}=4)$ grade 2 and $19 \%(\mathrm{~N}=4)$ grade 3 . In the left wrist, synovitis was $33.3 \%(\mathrm{~N}=7)$ grade $1,14.2 \%(\mathrm{~N}=3)$ grade 2 , and $14.2 \%$ $(\mathrm{N}=3)$ grade 3 . PDUS was seen in $23.8 \%(N=5)$ of the right and left wrists. In the right wrist, $9.5 \%(\mathrm{~N}=1)$ were grade 2 and $19 \%(\mathrm{~N}=4)$ were grade 3 . In the left wrist, $16 \%(\mathrm{~N}=4)$ were grade 2 and $4.76 \%(\mathrm{~N}=1)$ were grade 3 (Figures 1 and 2).

The Spearman correlation coefficient at the $\mathrm{P}<0.05$ level of significance revealed the following significant correlations: GSUS and swollen right wrist $(r=0.546)$, GSUS of right wrist and swelling of left wrist $(r=0.511)$, PDUS of right wrist and pain in left wrist $(r=0.436)$, PDUS of right wrist and CRP $(r=0.466)$. At the $P<0.001$ level of significance, the following correlations were obtained: GSUS and PDUS of right wrist ( $r=0.730)$, GSUS and PDUS of left wrist ( $r=$ $0.758)$, PDUS of right and left wrist $(r=0.732)$, GSUS of right and left wrist $(r=0.552)$, PDUS of left wrist and GSUS of right wrist $(r=0.574)$, PDUS of right wrist and GSUS of left wrist $(r=0.687)$, as presented in Table 2 .

The detection of synovitis by GSUS was higher than by PDUS. This may have occurred because a unit of frequency for low power Doppler was used. This may have caused the

Table 1. Drugs used by the patients at the time of examination.

\begin{tabular}{lccccc}
\hline & Prednisone & Methotrexate & Leflunomide & Chloroquine diphosphate & Hydroxychloroquine \\
\hline Percent of patients (N) & $52 \%(11)$ & $57 \%(12)$ & $14 \%(3)$ & $14 \%(3)$ & $9.5 \%(2)$ \\
Dose (mg) & 10 & 12.5 & 20 & 250 & 400 \\
Time of use (months) & 4 & 3 & 2 & 8 & 1 \\
\hline
\end{tabular}


underestimation of the capture of active microcirculation, which is always important in the evaluation of synovitis by GSUS.

There was no significant correlation between wrist GSUS and PDUS and DAS28, HAQ score or radiography. The as- sessment of intra-observational (same reader) Larsen score for the X-ray had a mean kappa value of 0.185 and there was no agreement with a semi-quantitative ultrasound scale, since only radiographic osteopenia of the carpal bones and soft tissue edema of both wrists was detected.
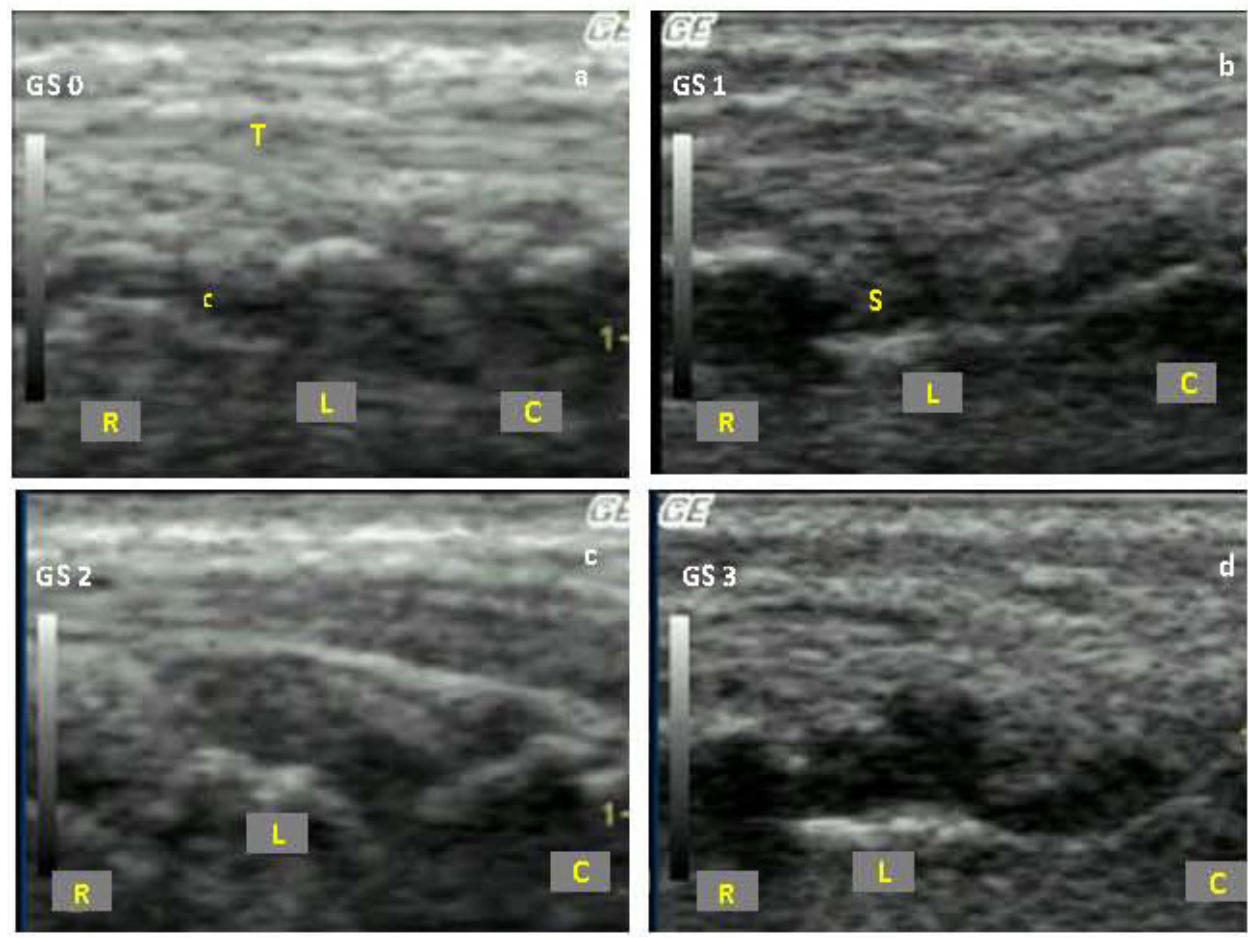

Figure 1. Synovitis identified by gray scale (GS) ultrasound in a dorsal longitudinal wrist scan. $a=$ grade $0 ; b=$ grade $1 ; c=$ grade $2 ; d=$ grade $3 . T=$ tendon; $S=$ synovitis; $R=$ radius; $L=$ lunate; $C=$ capitate bone; $c$ = cartilage .
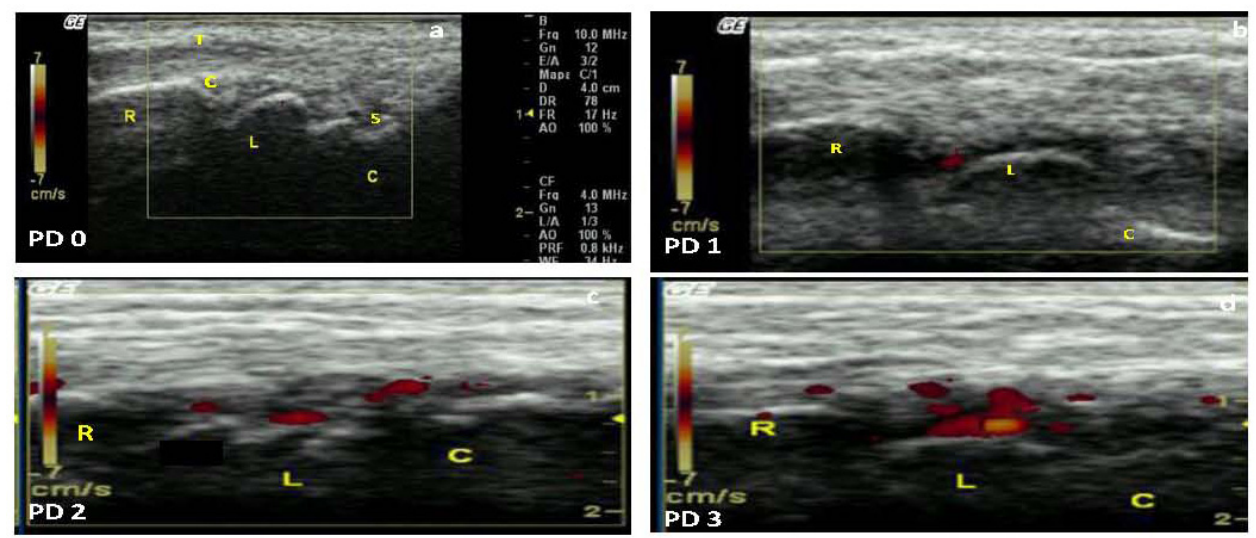

Figure 2. Synovitis identified by power Doppler (PD) ultrasound in a dorsal longitudinal wrist scan. a $=$ grade $0 ; \mathrm{b}=$ grade $1 ; \mathrm{c}=$ grade $2 ; \mathrm{d}=$ grade $3 . \mathrm{T}=$ tendon; $\mathrm{S}=$ synovitis; $\mathrm{R}=$ radius; $\mathrm{L}=$ lunate; $\mathrm{C}$ $=$ capitate bone $; \mathrm{c}=$ cartilage . 
This study showed an important correlation between the clinical and laboratory data, such as the correlation of the CRP and ultrasound data.

\section{Discussion}

In the present study, 42 wrist joints were evaluated by ultrasound in a population with very early RA characterized by 14 months of disease. PDUS showed significant synovitis changes indicated by the existence of active microcirculation in the joint capsule, as demonstrated by a semi-quantitative scale. PDUS and GSUS are important tools for confirmation of synovitis, which can be dissociated from the clinical findings, as reported in the literature (7). A positive and significant correlation between GSUS and PDUS of both wrists may characterize the symmetry of clinical involvement of the joints in RA. Thus, these variables detected by ultrasound could enhance the clinical diagnosis of early RA, even when CCP and the rheumatoid factor are negative. When we evaluated the level of intra-observational agreement (kappa) between the results of ultrasound and the X-ray data a discrepancy was identified, e.g., the number of changes seen by ultrasound in patients with early RA was higher than that seen by the X-ray, and the changes
Table 2. Correlation between clinical and ultrasound examination.

\begin{tabular}{lcccc}
\hline & \multicolumn{4}{c}{ Clinical and ultrasound data } \\
\cline { 2 - 5 } & Pain & Swelling & GSUS synovitis & PDUS synovitis \\
\hline Right wrist & $14(66.6 \%)$ & $16(76 \%)$ & $14(66.6 \%)$ & $5(23.8 \%)$ \\
Left wrist & $13(61.9 \%)$ & $14(66.6 \%)$ & $13(61.9 \%)$ & $5(23.8 \%)$ \\
\hline
\end{tabular}

Data are reported as number with percent in parentheses. GSUS = gray scale ultrasound; PDUS = power Doppler ultrasound.

found in the X-ray of the wrists were edema of soft tissues or osteopenia. The treatment of the RA has greatly progressed and currently intends to induce clinical remission based on the hypothesis that the inflammatory process leads to structural damage. Thus, there is a need to change the focus of evaluation, using a method that characterizes structural changes in the joint rather than only edema or osteopenia (26).

The ultrasound is important in the practice of the rheumatologist to prevent future structural damage, providing more comfort to the patient by fast, unlimited and safer scanning without irradiation. It can be considered a useful tool in the diagnosis of synovitis in early RA and can lead to an early change in the therapeutic decision.

\section{References}

1. Filippucci E, lagnocco A, Meenagh G, Riente L, Delle Sedie A, Bombardieri S, et al. Ultrasound imaging for the rheumatologist. Clin Exp Rheumatol 2006; 24: 1-5.

2. Grassi W, Salaffi F, Filippucci E. Ultrasound in rheumatology. Best Pract Res Clin Rheumatol 2005; 19: 467-485.

3. Kane D, Bruyn G, Arnold E, Grassi W. A rheumatologist's perspective on musculoskeletal ultrasound in rheumatology: comment on the editorial by Roemer et al. Arthritis Rheum 2006; 55: 341-342.

4. Kane D, Grassi W, Sturrock R, Balint PV. Musculoskeletal ultrasound - a state of the art review in rheumatology. Part 2: Clinical indications for musculoskeletal ultrasound in rheumatology. Rheumatology 2004; 43: 829-838.

5. Brown AK, O'Connor PJ, Roberts TE, Wakefield RJ, Karim Z, Emery P. Recommendations for musculoskeletal ultrasonography by rheumatologists: setting global standards for best practice by expert consensus. Arthritis Rheum 2005; 53: 83-92.

6. Grassi W, Filippucci E, Carotti M, Salaffi F. Imaging modalities for identifying the origin of regional musculoskeletal pain. Best Pract Res Clin Rheumatol 2003; 17: 17-32.

7. Bresnihan B, Kane D. Sonography and subclinical synovitis. Ann Rheum Dis 2004; 63: 333-334.

8. Wakefield RJ, Green MJ, Marzo-Ortega H, Conaghan PG, Gibbon WW, McGonagle D, et al. Should oligoarthritis be reclassified? Ultrasound reveals a high prevalence of subclinical disease. Ann Rheum Dis 2004; 63: 382-385.

9. D'Agostino MA, Ayral X, Baron G, Ravaud P, Breban M, Dougados M. Impact of ultrasound imaging on local corticos- teroid injections of symptomatic ankle, hind-, and mid-foot in chronic inflammatory diseases. Arthritis Rheum 2005; 53 : 284-292.

10. Koski JM, Helle M. Ultrasound guided synovial biopsy using portal and forceps. Ann Rheum Dis 2005; 64: 926-929.

11. Balint PV, Kane D, Wilson H, McInnes IB, Sturrock RD. Ultrasonography of entheseal insertions in the lower limb in spondyloarthropathy. Ann Rheum Dis 2002; 61: 905-910.

12. Naredo E, Cabero F, Beneyto P, Cruz A, Mondejar B, Uson $\mathrm{J}$, et al. A randomized comparative study of short term response to blind injection versus sonographic-guided injection of local corticosteroids in patients with painful shoulder. J Rheumatol 2004; 31: 308-314.

13. van Gestel AM, Haagsma CJ, van Riel PL. Validation of rheumatoid arthritis improvement criteria that include simplified joint counts. Arthritis Rheum 1998; 41: 1845-1850.

14. Ferraz MB, Oliveira LM, Araujo PM, Atra E, Tugwell P. Crosscultural reliability of the physical ability dimension of the health assessment questionnaire. J Rheumatol 1990; 17: 813-817.

15. Ciconelli R, Ferraz M, Santos W, Meinão I, Quaresma N. Tradução para a língua portuguesa do questionário de avaliação de qualidade de vida SF-36 (Brasil SF-36). Rev Bras Reumatol 1999; 39: 145-150.

16. Grassi W, Tittarelli E, Blasetti P, Pirani O, Cervini C. Finger tendon involvement in rheumatoid arthritis. Evaluation with high-frequency sonography. Arthritis Rheum 1995; 38: 786794.

17. Manger B, Kalden JR. Joint and connective tissue ultra- 
sonography - a rheumatologic bedside procedure? A German experience. Arthritis Rheum 1995; 38: 736-742.

18. Fiocco U, Ferro F, Vezzu M, Cozzi L, Checchetto C, Sfriso $P$, et al. Rheumatoid and psoriatic knee synovitis: clinical, grey scale, and power Doppler ultrasound assessment of the response to etanercept. Ann Rheum Dis 2005; 64: 899905.

19. Taylor PC, Steuer A, Gruber J, Cosgrove DO, Blomley MJ, Marsters PA, et al. Comparison of ultrasonographic assessment of synovitis and joint vascularity with radiographic evaluation in a randomized, placebo-controlled study of infliximab therapy in early rheumatoid arthritis. Arthritis Rheum 2004; 50: 1107-1116.

20. Szkudlarek M, Klarlund M, Narvestad E, Court-Payen, Strandberg C, Jensen KE, et al. Ultrasonography of the metacarpophalangeal and proximal interphalangeal joints in rheumatoid arthritis: a comparison with magnetic resonance imaging, conventional radiography and clinical examination. Arthritis Res Ther 2006; 8: R52.

21. Backhaus M, Ohrndorf S, Kellner H, Strunk J, Backhaus TM, Hartung W, et al. Evaluation of a novel 7-joint ultrasound score in daily rheumatologic practice: a pilot project. Arthritis Rheum 2009; 61: 1194-1201.

22. Kaye JJ. Radiographic methods of assessment (scoring) of rheumatic disease. Rheum Dis Clin North Am 1991; 17: 457-470.

23. Plant MJ, Saklatvala J, Borg AA, Jones PW, Dawes PT. Measurement and prediction of radiological progression in early rheumatoid arthritis. J Rheumatol 1994; 21: 1808-1813.

24. Larsen A, Dale K, Eek M. Radiographic evaluation of rheumatoid arthritis and related conditions by standard reference films. Acta Radiol Diagn 1977; 18: 481-491.

25. Larsen A, Thoen J. Hand radiography of 200 patients with rheumatoid arthritis repeated after an interval of one year. Scand J Rheumatol 1987; 16: 395-401.

26. Hafstrom I, Albertsson K, Boonen A, van der Heijde D, Landewe R, Svensson B. Remission achieved after 2 years treatment with low-dose prednisolone in addition to diseasemodifying anti-rheumatic drugs in early rheumatoid arthritis is associated with reduced joint destruction still present after 4 years: an open 2-year continuation study. Ann Rheum Dis 2009; 68: 508-513. 